\title{
Views of a Luddite
}

The future of academic libraries seems to be both a promise and a threat. We are experiencing great changes in the ways in which we store and retrieve information. Consequently, the nature of libraries and their use is also changing dramatically. Will the promised benefits - now more urgently sought than ever, in the face of mounting fiscal problems-also undermine traditional scholarly values? Libraries are, above all, social systems: a teaching-learning milieu in which retrieval of information is only a part. If the new technology destroys this environment, it will also destroy what it is trying to maintain and improve.

I AM PLEASED to be invited to speak about what the next decade might mean to my work as a teacher and researcher because so much of my work and my enjoyment depends on libraries and librarians. What happens to librarians will also happen to me. In fact, my temperament and training are such that, where others would turn to a crystal ball, a computer projection, or their own imaginations to approach today's theme, I went to the library. Or, more technically, I began a documents search for materials on what libraries might be like ten years from now. I clipped articles from Change and the Chronicle of Higher Education (my own copies!), I turned to my reference librarian - my friend and colleague Evan Farber - and I read all the material he put in my hands. I also tried to experience what the future will be like by pursuing three computer searches of databases - one in modern poetry, one in the history of British dissenting academies, and one in a new therapy in psychology.

As you know from your own work, the predictions about these next ten years contain good news and bad news. The bad news is that no library will be adequate, in itself, to meet all the demands that will be placed on it; and that the cost of acquiring new materials - which will continue to pour forth in geometrically increasing quantities - will continue to rise so steeply that every aca-

Paul A. Lacey is Bain-Swiggett professor of English literature and language, Earlham College, Richmond, Indiana. demic and university library will have to become more selective in its own holdings. Some colleges are planning to stabilize their collections at some specific number of volumes (rather than increasing holdings indefinitely), then maintain that number by careful culling, on the one hand, and vigorous use of cooperative and network arrangements, on the other, to supply what students and faculty need. The good news, of course, is that such cooperative arrangements, networks, and computer-accessible databases are already largely in place and at present make far more material available to the researcher than ever before. Moreover, it is good news that computer indexing of databases will be followed rapidly by immediate computerized access to the documents themselves. A recent New York Times article on the computerization of the Library of Congress catalog notes that the electronic catalog now has 81 million entries, with room for scores of millions more, and that in the future electronic processes will allow the retrieval of actual book contents on the cathode screen. In the future, we also know, it will become ever more common that such retrieval of materials will allow for hard-copy reproduction as well.

We are in the middle of a sweeping revolution in the ways we generate, collect, store, retrieve, and use the products of the human mind - the products we rather casually call information or data. Work that would previously have taken years of drudgery to accomplish will be done in a fraction of the time and of the drudgery. Questions that would not 
have occurred to us to ask, because their answers would have required methods of comparison and analysis too complex to keep straight in our minds, might soon be commonplace to ask and answer. The very forms in which we index and catalog materials will permit multiple studies in word frequency, stylistic profiles, concordances, and the like - to speak of only one kind of literary study. Problems involving many variables can be studied in ways too complicated to have been attempted in the past. The very ways we collect and store information will produce more information; we will be able to wring out the last drop of significance from every piece of data-which is the scholar's dream.

As this brief survey of what is already happening reminds us, the ways we use libraries in the future are likely to be vastly different from what they have been in the past. Some of the predictions I have read speak exultantly of the end of libraries as we have known them, the end of dependence on print, and the end of the book. In place of the vast building with its many holdings and many services, the most radical predictions envisage the "disembodiment of the library," and in its place a system of information retrieval operated by a keyboard at the scholar's desk. They see the scholar alone in his or her office, typing out instructions that will call up, in moments, virtually anything that has ever been committed to print or entered into a memory bank. According to this vision, publishing will also change radically; articles and books will be entered directly into a memory bank or database, to be called up if and as anyone is interested. Books will virtually disappear - not only as physical objects, print on paper, but as extended argument or discussion. "Instead, bibliographic technicians will have already broken down the book into fragments suitable for storage in giant computers and for transmission through a variety of audio-visual systems."1 No one will want to labor to make a book a coherent whole if everything of that sort is destined to be dismantled into fragments suitable for storage and retrieval.

Perhaps you've noticed that I stopped talking about good news and bad news. That is because I am no longer sure whether what I am describing is one or the other. I see the marvelous possibilities in having so much material so readily available, but I also recognize that the technological developments that are confidently predicted to lead to the end of print, the end of the book, and the end of the library, strike me with horror. I cannot imagine doing my work as a teacher and a researcher with pleasure in such a world.

By training and interest I am a teacher and student in the humanities. I spend my professional time, and much of my recreational time, reading literature and making connections between literary works and between literature and other disciplines - especially psychology, philosophy, theology, and history. Like the majority of college and university teachers in America, I see myself primarily as a teacher. I write and publish modest amounts, and I keep a number of research projects working all the time, but virtually all of my writing and research relates directly to my teaching, which in turn grows largely out of my intellectual interests. I am drawn not only to aesthetic questions, but to social, political, and philosophical ones, and these help shape what I teach and how I do research to prepare for my teaching.

My job, then, is to read literature carefully, to understand what writers have written and the contexts out of which their writings have come. I do this job for my own satisfaction - for the pleasure I receive from the beauty of literature, from the wisdom and the insight into human motives and actions it offers, and from the truth it contains. I also do this job because it brings me into meaningful relations with other people-my undergraduate students and my teaching colleagues - with whom I share the pleasure, beauty, wisdom, insight, and truth of literature.

As a teacher and a student of literature, my methods are analytical, but I am ultimately concerned with wholes rather than with parts. My effectiveness must be judged according to how well I bring the whole text, the complete work, before my students, and how well I demonstrate my respect for the whole text in my attention to the smallest detail. I must, in turn, assess the value of a library or an information-retrieval system by how well they help me come to a close, informed examination of a whole text.

As a teacher and a student of the humani- 


\section{2 / College \& Research Libraries • March 1982}

ties, I must come clean on something else about myself that profoundly influences how I look at what will be happening to libraries in the next ten years. I am a Luddite. The first Luddites-named for an English factory worker who was said to be mentally retarded-broke machinery that was threatening to put them out of work. To say I am a Luddite is to say I approach technological developments, which others call progress, with fear and hostility, and my stock reaction to the introduction of a new piece of machinery into my life is to hope it will break down ignominiously. I love to see machines fail, and I believe they reciprocate the feeling. My experiences with computerized technology have frequently been catastrophic. The only time I ever tried to withdraw money from a bank machine was on a Saturday afternoon, just before I was to leave on a business trip. The machine housed a persona named something like Auntie Em - warm, chatty, eager to help. In the middle of our transaction, Auntie Em ate my card and then pretended never to have heard of me. When in desperation I left to make a futile effort to phone someone from the bank, the public telephone swallowed my only dime. Like most Luddites, I am selective as well as ambivalent about the technology I wish to eliminate. I drive a car, fly in airplanes, use the telephone, radio, and television, but deep down in my heart $I$ have only accepted the radio fully. I prefer to write with a fountain pennot even a cartridge pen but a real fountain pen. Do not expect me to greet the future with unalloyed pleasure.

Undoubtedly my feelings are made up of a lot of sentimentality and wrongheadedness, but let me indulge them for a few minutes because there are a great many people like me-perhaps especially among people in the humanities - and what we can foresee as the shape of our work in the future rests only in part on what technology can offer us. The larger part rests on how we feel about what technology can do for us. The first Luddites were weak, fighting a desperate losing battle; those I am talking about are strong and influential; they can make systems fail simply because they will not cooperate. So, for a few minutes, I will indulge myself.

I have strong emotions about libraries. The feel and look of books matter to me. I love the touch and smell of a clean new book and an old leather-bound secondhand one. Every library I have ever worked in evokes memories of the first one I used, a branch public library in a bankrupt grocery store on a side street in Philadelphia. When I was a child, I not only played cowboys and war and school; I also played library. I put cards in my books, and I used to like to hold my pencil between my first and second fingers, the way librarians did when they wrote in one's card number and then reversed the pencil to stamp in the date. The library not only had the books one wanted, it was a place to be on rainy Saturdays. It had heavy oak tables to sit at and read; it was intimate and personal and run like a cottage industry. It was a mom and pop library. In the years since then I have learned to use bigger and better libraries - Widener, Houghton, the New York Public, the British Museum, and many others - but they have all felt familiar to me because they were still essentially cottage industries.

But of course libraries have also changed enormously since the days when the librarian wrote your card number on the book card and then stamped the date. I recall when I first became aware of the rapidity of the changes. I was finishing college at the University of Pennsylvania in 1957, and the university was just beginning to use a computer for course registration. (I recall with pleasure that the first experiment was disastrous.) Several of us found ourselves speculating about how this new thing could be used in libraries. We spent a hilarious couple of hours capping each other's wildest fantasies about what might be possible with the new technology. I recognize now that every outrageous science fiction invention we imagined has since been surpassed by what happens every day now with computer searches, telephone transmission of printed data, and new forms of bibliographies, concordances, and indexes. I mention this not only to put you on your guard about me as a forecaster but also to put in stark relief the differences between the library of my memories and the library I seem to be destined to work in in the future.

If I were a Luddite only out of nostalgia and mechanical incompetence, I would not be worth listening to; but even when we have been wrongheaded, we Luddites have raised important value questions. The first Luddites 
had three anxieties that you and I, and our colleagues, must also face now and in the decade ahead. They can be put in the form of three questions:

1. Will the new technology put us out of meaningful and valuable jobs?

2. Will the fine old crafts we practice be cheapened or lost as a result of the new technology?

3. Will the new machinery alienate us from our work and from our fellow workers?

These, I suggest, are crucial questions for us to ask as we speculate on what will happen in the study of the humanities in the next ten years, and I will try to reflect on each in some detail.

Will the new technology put us out of meaningful and valuable jobs?

I have already indicated that I am a teacher first of all, and a researcher in large part as a result of my teaching. My work, then, brings me into close and rich association with people who study as well as produce literary works. Dame Helen Gardner describes the study of literature this way:

In no other subject is the pupil brought more immediately and continuously into contact with original sources, the actual material of his study. In no other subject is he so able and so bound to make his own selection of the material he wishes to discuss, or able so confidently to check the statements of authorities against the documents on which they are based. No other study involves him so necessarily in ancillary disciplines. Most important of all, no other study touches his own life at so many points and more illuminates the world of his own daily experience. ${ }^{2}$

Both studying and teaching literature are, preeminently, library work. To teach a student how to study literature is to introduce him or her to systematic library research methods - going to original sources, selecting judiciously, checking authorities against the documents, reaching out into other fields of study to get more light on the meaning of our documents. Such study is an end in itself and the means to other ends. It teaches us how to read accurately, and in the process it lets us share the pleasure, beauty, insight, and wisdom that literature offers to those who approach it with openness and respect. Will technology put me out of that job, or are there ways it can enhance and extend the effectiveness of that work-whether or not I am the one who does it?

My ultimate end may be to find truth and beauty in literature, but my means require making discriminations, studying fine details. Analysis must precede synthesis. In these kinds of tasks, which Professor Donald Bond has called "scholarship preparatory to scholarship," new technology is invaluable. Discovering and classifying documents, making descriptive bibliographies, editing texts, establishing sources and analogues are essential but painfully time-consuming tasks. Now indexes and bibliographies can be searched in instants instead of weeks. Collating editions, textual studies, concordances, wordfrequency counts and stylistic profiles, formerly among the slowest, most tedious of work, can now be done with the assistance of the computer in a fraction of the former time and quite possibly with more fertile results, since the computer-generated tracings and cross-references can help us see far more elaborate or deeply embedded literary patterns than we have seen before. To cite a single example, the Chronicle of Higher Education (March 16, 1981, p.19) reports that Professor Colin Martindale of the University of Maine at Orono used a computer to trace trends in language usage among English poets over a five-hundred-year period. Choosing the work of five leading poets in twenty-year time periods, Professor Martindale fed fiftyeight line samples of each poet's work - taken at random - into the computer. The resulting computer analyses showed a trend in each period toward "incongruous or unpredictable imagery as the younger poets within the tradition succeeded." And as one tradition gave way to another, the new poets wrote once more "in more familiar images." According to Professor Martindale, this study would have been difficult if not impossible without the computer.

Historical and critical approaches, literary biography, social history, intellectual history, and a variety of cross-disciplinary approaches to literary works may in time all be made less exhausting as more and more relevant material gets entered into memory banks. Surveys of lists, book-sale records, names on registers, wills and legal documents are some of the raw material of such studies. Meyer Abrams has described indifference to boredom as "the sine qua non of scholarship," 


\section{4 / College \& Research Libraries • March 1982}

but it is possible that in the future we will be able to get more useful conclusions out of our surveys of such material at the cost of less weariness of flesh and spirit.

The kinds of scholarly tasks I have been describing, though they are highly valuable, are only a small part of what students of the humanities find useful to do. Moreover, not everything we might want to examine minutely will be fed into a computer in time for us to avoid the tedium of a hand search; indeed, most of such tedious material will get into a computer only after someone has gone through it minutely to program it. And despite all the promise of easy access, there will have to be selections of what is going to be made retrievable in the great databases. Even if microforms and computer memory are easy to store, the expense of collecting material will continue to increase, as will the cost of retrieving it. The librarian who helped me with my computer searches discouraged one line of approach by saying gently that computer time was pretty expensive for playing around. He is right, of course, but we must remember that playing around, hunting and poking around in unexpected places, imagining unorthodox ways to get at information, are the very heart of research. Playing around is cheap when only the scholar's time is being considered, since in fact we never put an hourly cost to that, but when we have to pay for machine time instead of human time, we may find that some things we would like to do simply are not affordable.

Information is not merely exploding, it is undergoing fission. Even the great storage capacity we have will not allow us to keep up with the rapidly moving present while simultaneously reaching ever more deeply into the distant past. For economic reasons, if no other, we may be unable to do both. Some of the more radical projections of changes in research methods acknowledge, perhaps a bit condescendingly, that people who deal in earlier ages will still have to look at books, original documents, and other antique data sources. I hope they will not waste too much pity on us, for that is our greatest strength. As C. P. Snow pointed out, whereas something like 90 percent of the natural scientists who have ever lived are alive now, about 90 percent of the writers who have ever lived are dead. Snow thought that the latter fact was regrettable, but I consider it a great benefit. The humanist does not live only in the immediate present or in anticipation of a swiftly arriving future; he or she lives in distant times or several ages. The humanist is a time traveler into the past, studying and honoring and seeking to understand writers whose canon is forever closed, writers who, in representing their own time, offer something for ours.

What I say about literary study also applies to much philosophical, theological, and historical work. Plato and Thucydides, Isaiah, Socrates, and Jesus are not our contemporaries, but they speak to us precisely because they are so deeply rooted in the existential problems of their times and places. Will the new technology put us out of meaningful and valuable jobs? No. The new technologies have enormous promise for us, but not everything we consider worth doing will benefit from the laborsaving new machines. Some things will never get into the memory banks or will be too expensive to call up in meaningful form. This cautionary point leads directly into the Luddite's second question.

Will the fine old crafts we practice be cheapened or lost as a result of the new technology?

This is not a trivial question. We know already how easy it is to let machines dictate what we will do. Natural scientists find themselves deciding to study one topic rather than another because they have the necessary equipment to study the first topic. The equipment may not only determine what we will study, it will significantly determine what will be accepted as meaningful data. A number of scientists and philosophers have warned against the growing tendency to let what we study, how we study it, and what will be taken as acceptable conclusions to our study be determined by the equipment we have available. We know how hard it is to go outside the limits of the field, however they are established, yet just that breaking the limits of the field, conceiving of new ways to approach a topic, is what vitalizes research. It is not merely fear of the future, or sentimental longing for the past, that leads the humanist teacher and researcher-like our counterparts in the natural and social sciences-to worry about the craft of research, the skill of mind and hand and eye that turns up the fruitful lead, or the telling 
bit of information. That craft can be lost if we do only what the machinery knows how to do rather than what we believe is worth doing.

What is the craft of research? For me it is being able to frame a significant question. This is the same craft which is at the heart of teaching. To frame a question means making a judgment about what is worth asking on a subject, what will produce the most important connections between ideas and bits of information, and what can lead us into more sophisticated or far-reaching questions. In speaking of framing rather than asking questions, I am trying to get at the process by which one examines a body of material, an event or a phenomenon at the same time as one examines the tools or the means by which a further examination of the subject can be best made. Framing the question is not simply requesting information; it is more like framing up a building, that preliminary roughing out of the space one is going to occupy, putting in the supports that allow one to do the substantial building in a more orderly fashion. I have to consider the materials I have to work with, the terrain I am working in, the tools I have at my disposal. If I am framing a question, I have to ask what I want to know and how I am likely to find out what I want to know in the most dependable fashion.

As a teacher I ask myself what I want my students to be able to do after they have reviewed research, what I want to come out of their writing of papers, what form I want those papers to take - and all of that leads me to thinking how my assignment should be constructed. When I am most fully engaged in reflecting on these questions, I am framing the questions that will organize a course within the content to be examined and what my students will be able to do with it.

For those of us in the humanities and social sciences certainly, and for natural scientists pretty substantially, the library is the most important and largest toolbox we have for framing our questions. Yet most of us who are teachers and researchers are poorly instructed in how to use the tools a library provides. We have been accustomed to having the hardest courses we took and the hardest we teach introduce the longest list of books on reserve. Our professors gave us fine bibliographies that directed our reading, and we may do the same for our students. Often it has been our experience that the most challenging graduate seminars we took specified both the paper topics and the works we were to consult. Our best graduate and undergraduate courses gave exclusive attention to mastering the content of major works in our field. We would go to a reference librarian as a last resort, and rarely if ever imagine that we could learn a generalizable method of research that might give us more interesting questions to pursue.

Several consequences flow from that kind of experience. We are only experienced in a very small part of the research tools a library offers. We only know a small part of a library's holdings - the eighteenth century or the American colonial period. Because of our limited, though deep, experience with a specialized set of holdings and the specialized tools for studying them, we may automatically turn away from stimulating new questions to work in the safe and familiar. We become passive in the presence of a new problem. We decide it is uninteresting or impossible to pursue. I consider myself quite at home in a library, but I occasionally catch myself evading a topic when a preliminary survey shows that it will not yield to my standard methods. Confessing ignorance is good for us, we know, but most of us will pass up the opportunity to admit our ignorance, when we can. In this connection it is worth noting that approaching a database through programs that are not, in the jargon, "user friendly," is far more daunting than asking a librarian for help in a strange new area.

We also like to postpone wrestling with the hard work of a study, making the material make sense, constructing the questions that will probe the data. Dreary though note taking is, it is not the hard work of thoughtwhich is what we tend to avoid when the problem we are studying is resistant. Have you noticed how often people stand feeding coins into the Xerox machine, copying pages, instead of reading the pages to decide which are really worth having? Searching for more material is a familiar way for avoiding coming to grips with what one already has. Research technologies that show us how to amass great quantities of bibliographies, indexes, lists, bits of books, may - unless we do something about learning a more subtle 
craft - cause our ability to frame questions to deteriorate even further.

So behind the question of whether the new technology will ruin our craft lie two concerns. First, there is already a danger that researchers ask only the questions they are certain they have the means of answering. We and our students can become passive and ask only what our machines can answer, rather than venturing beyond those limits. Second, for people who are already overspecialized and too narrow in their acquaintance with a library, the kinds of new technologies we have may help confirm the overspecialization, both because they let us mine familiar territory more extensively and because they are daunting when we enter new territories. One of my computer searches came to a temporary standstill as the printout repeated "invalid command" time after time, while my helper, trained to negotiate such obstacles, tried unsuccessfully for about ten exchanges to puzzle out what would satisfy this mechanical servant which had just become so finicky. Need I say that, had I been on my own, I would have typed something like "Forget the whole mess, let me out of here"? Of course, the machine would have replied "invalid command," and my private nightmare would have continued.

To put the matter as I have is to remind us of the maxim that it is a poor craftsman who blames his tools when something goes wrong. The enormous possibilities of new technology show us that many of us, both as teachers and researchers, have asked the same kind of question again and again about familiar material and have done the same research project on several different texts. We have had little experience in framing new questions, new approaches. It is universally agreed that there is a great deal of garbage being published in all fields, but how do we deal with that fact when we ask for a research paper from students? Typically, such papers are required to begin with a thorough review of the literature, and the student is rewarded for going through the literature with the thoroughness and indiscriminacy of a powerful vacuum cleaner. Apparently we see no way of dealing with the garbage except to wade through all of it. The computer will not solve that problem for us. Technologies that produce longer lists of titles, more piles of data, and which break books down into fragments for suitable storage cannot, in themselves, give us better research.

In speaking of the value of social science indexing for perceiving complex social systems, Kenneth Boulding has said, "It is fundamental to all knowledge that we gain knowledge by the orderly loss of information." Most of us, at the start of our careers as teachers and researchers, assumed that one never dared to lose any information. It was always to be piled on more and more; knowledge was the sum total of one's information. That is a false model of learning, but some of the most exultant celebrations of the libraries of the future speak of research and learning only under that model. Will the new technology make us lose or cheapen our crafts as researchers? It will not, in itself, either cheapen or improve our craft. That depends on us. Computer databases will be selective and discriminating only if we tell them to be so. They make a craft possible, but they are not a craft in themselves. This brings me to my third Luddite question.

Will the new technology alienate us from our work and from our fellow workers?

That question has to be considered on at least two levels. I have already begun to address one level in discussing the problems by considering study and research as first and foremost the amassing of data. To work in the humanities means to treat the text, the original source, with the utmost respect. Every piece of research we do ought to have as a major goal bringing us closer to the text, to the composer of the text, and to the society that created it. Our study ought always to be a celebration of human hopes and accomplishments. Counting word frequencies or beating out a poem's meter on the desk top may be very far away from these noble goals, but they must somehow participate in these goals or they mean nothing. As teachers and researchers in the humanities, some of our most significant work involves not great quantities of material but a small body of material studied deeply. As I have suggested, that is both a strength and a problem.

On the second level we must consider research as a social activity, something that we do with other people. The stereotype of the scholar in the humanities places him or her in a lonely study, occasionally sending a little 
signal to the outside world in the form of an article, learned note, or query. Scholarship is something we do alone, but we also pursue it in company. Not only do we want to be in touch with those who are working on similar issues, we want friends and colleagues around - working on very different things who can share with us the delight in a new insight, a fruitful line of inquiry.

When I first started teaching at Earlham, there was only one coffee urn in our building. If one went for coffee, it was with the expectation of spending half an hour or longer. One was away from the desk and the telephone, and more important, one was with colleagues from the whole faculty. A lot of very good conversations generated a lot of good ideas while we were drinking coffee. As time went on, people started thinking it would be cheaper and more efficient if departments bought their own coffeepots, so we would not have to walk three flights to get coffee or expect to spend half an hour over it. And now, to be sure, every department has its coffeepot, and most of us walk across the hall, fill our cups, return to our offices, and keep on working. There are no half-hour breaks; I at least drink coffee all day long now, instead of three or four cups; and I see less of my immediate colleagues and virtually nothing of people in other departments unless I seek them out. The gathering place disappeared when we found a little bit of a timesaver to ease our work. The work, perhaps, is also less satisfying, because it is not shared with others.

If advances in information retrieval technology really lead to every scholar sitting at a console, calling up data and books and articles in splendid isolation, I believe we will be the worse for it, just as we will be worse off if "publishing" comes to mean dropping one's little pebble of information into the deep well of a database with no hope of hearing the faintest splash. The projections that foresee the disappearance of libraries, and librarians working themselves out of a job, fill me with despair, unless I conclude that what those writers mean by a library is very different from what I mean.

Let me acknowledge once again that books have great aesthetic appeal to me, and I love to browse through stacks of them. But I do not think of a library as simply a giant ware- house for books. If the library of the future becomes a storehouse of computer memories and microforms, rather than of books, my aesthetic enjoyment will be reduced; but that is really a minor consideration. For a library is far more than a storage or retrieval center. At its best, a library is a model for the teaching-learning process. I am going to describe that model, using the Lilly Library at Earlham College, which I know best, but intending to make the model widely generalizable.

First of all, the building is designed for a multiplicity of uses, all of which are essentially voluntary. Materials for both information and enjoyment lie close at hand. One may come in to read the newspapers or magazines, check an atlas, look something up in an encyclopedia. One may think of the library the way George Bernard Shaw thought of marriage, as combining the maximum opportunity and the maximum temptation. Databases may have everything available and up-to-date that I have described, except the context. Browsing in a database-a form of play that is "rather expensive" - will never be the same as walking through a space with so many different temptations drawing the eye. The library user-often called a patron-identifies what he is looking for; if he cannot find it he goes to a librarian for help. The librarian engages in conversation with the patron, drawing out more about his interests and needs. The patron may be shown where to find what he wants; taught how to find it and things like it in the future; or helped to see that he actually wants something very different. That is, to think of the college situation, in the process of describing his interests or his assignment, and learning what the library is best equipped to provide, the patron may have his wants refined and redirected. The process helps him frame his question better. That clarification process can be helped by computer searches, but I think its most important aspect is that it is a conversation between two people face-toface. More than information is transmitted in that conversation; attitudes, values, tone of voice, respect, and human interest all are part of that conversation. Every research project needs something to give it human scale. That is research as a social activity.

Such a library provides a learning milieu 
that is ideal for independent study - for both the beginner and the experienced researcher. The librarian acts as a facilitator, giving a great deal of help and advice but leaving the patron to do the actual work. As a general rule, the librarian is not involved in evaluating the researcher's performance.

The library I am describing has seminar rooms, typing rooms, lounges, a faculty lounge, smoking rooms, a variety of carrels, tables, and chairs for people to use in their reading and writing. There are rugs on the floors in some places, and it is not uncommon for us to see a student napping on the floor with books and papers beside him. The library has Xerox equipment and computer terminals, a language laboratory, and other audiovisual facilities. All this is available for people to take from as they wish, subject only to those rules about control of material and etiquette that make things available to the greatest number of users.

I want to emphasize my point here. I am not conceiving of the library as an information retrieval system primarily but as a social system, a teaching-learning milieu in which retrieval of information is only a part of the goal. Browsing, conversation, exchange of ideas, sharing and confirming values, supporting one another in the common enterprise of study, reflection, and publishing one's findings - these are extremely important to what a humanist, or any member of the scholarly community, does. Take them away, and we will be alienated from our work and our colleagues. Improved technology is a splendid help in accomplishing many of our tasks, but both the successful accomplishment of our work and the satisfaction we get from our work depend on the links with the community of scholarship.

I am arguing that the library is not merely a place or a collection of functions but a living symbol of valuable and rich human relations. One can listen to a church service on radio or television and be inspired by the sermon and the music; one can go to a drive-in church and see the service firsthand, while sitting in one's own "solitude covered with iron," as Robert Bly describes the automobile. But I find it very hard to believe that one can truly share communion by radio, television, or drive-in services. Communion, our deepest experience of self-transcendence, comes only in the closest association with other humans. And in our work as teachers and as researchers we know something of the joys of selftranscendence, being caught up in a text or a search that makes us forget ourselves, and we also know the joy of communion, of finding kindred spirits, dedicated scholars and writers who are a part of our human family. There must be places where such things can happen and be confirmed and memorialized. Universities and colleges are such places. So are libraries.

You may know that Lincoln Steffens had developed his phrase about the Russian Revolution before he ever got to see the revolution itself. On the train from Western Europe into the Soviet Union he was practicing the phrase: "I have seen the future, and it works." If I were the Luddite I have posed as, I would be practicing my own phrase-something like, "I have seen the future, but it is down at the moment." But of course it would be fatuous to wish that brilliant inventions fail, that laborsaving devices be replaced once more by mind-wearying drudgery. We can have the benefits of new technologies, along with the benefits of the best methods and goals of the past and present, if we are reflective about what we want from the machines we have created. With wisdom and care, we can find that the new developments in library and research technology in the decade ahead help us to do our jobs better, with more satisfaction, help us become more skilled and subtle craftsmen and craftswomen, and far from alienating us from work or one another, help us find richer associations and deeper communions. If those things happen, however, it will not be because or despite of machinery, but because the human spirit can express itself in the new ways as well as the old.

\section{REFERENCES}

1. F. Wilfrid Lancaster, "Libraries and Librarians in an Age of Electronics" (unpublished), p. 165 .

2. Dame Helen Gardner, "The Academic Study of English Literature," Critical Quarterly I (1959), III. 